\section{Catalytic Oxidation of Toluene on Hydrothermally Prepared Ceria Nanocrystals*}

\author{
M. Duplančić, ${ }^{* *}$ S. Kurajica, V. Tomašić, and I. Minga \\ University of Zagreb, Faculty of Chemical \\ Engineering and Technology, \\ Marulićev trg 19, Zagreb, Croatia
}

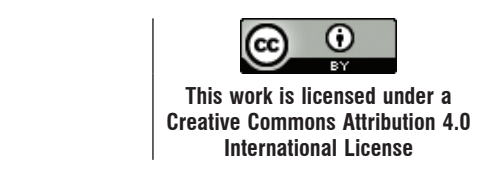

doi: 10.15255/CABEQ.2017.1098

Original scientific paper Received: February 20, 2017

Accepted: November 30, 2017

Ceria nanocrystals were prepared hydrothermally and tested as potential catalysts for oxidation of volatile organic compounds using toluene as a model compound. Pure ceria with a crystallite size of $4 \mathrm{~nm}$, determined by the Scherrer method from XRD pattern has been obtained. The specific surface area of the prepared nanoparticles determined by BET analysis yielded $201 \mathrm{~m}^{2} \mathrm{~g}^{-1}$, while the band gap of $3.2 \mathrm{eV}$ was estimated from DRS spectrum via Tauc's plot. Catalytic tests were performed on calcined ceria $\left(500{ }^{\circ} \mathrm{C}\right)$ with increased crystallite size $(9 \mathrm{~nm})$ caused by thermal treatment. The tests showed good activities for the toluene oxidation with $T_{50}$ temperatures, corresponding to $50 \%$ toluene conversion, observed at $250{ }^{\circ} \mathrm{C}$ and even lower temperatures depending on the total flow rate of the gas mixture. The one-dimensional pseudo-homogeneous model of the fixed bed reactor was proposed to describe the reactor performance and the appropriate kinetic parameters were estimated. Good agreement between experimental data and the proposed model was observed.

\title{
Keywords:
}

ceria, catalytic oxidation, nanomaterials, toluene, modelling

\section{Introduction}

Catalytic oxidation of monocyclic aromatics, such as benzene, toluene, and xylene, which belong to a wider group of volatile organic compounds (VOCs), has been the subject of many studies over the past 20 years, due to their toxicity and adverse effects on the environment ${ }^{1-7}$. Although several "end-of-pipe" techniques have been developed to remove VOCs from polluted air, such as adsorption, absorption, condensation, thermal combustion, and biofiltration, heterogeneous catalytic oxidation has been recognized as one of the most efficient and environmentally friendly techniques that can meet the criteria of permissible emissions into the environment $^{8,9}$. The most important advantage of catalytic oxidation in comparison to the more common thermal oxidation process is the fact that it requires little or no supplementary fuel, and therefore is a less expensive process ${ }^{4}$. Of course, it is important to emphasize that catalytic oxidation is less expensive only for relatively dilute streams of VOCs (which are the most prevalent in real situations), but for more concentrated gas streams, thermal oxidation is a much better solution ${ }^{4}$.

"Presented at the " $4^{\text {th }}$ International Symposium on Environmental Management - Towards Circular Economy (SEM2016), December 7 - 9, Zagreb, Croatia"

***Corresponding author: Marina Duplančić; Tel.: +385-14597194; Fax: +385-14597133; E-mail: marina.duplancic@fkit.hr
The high cost of noble metal catalysts (predominantly $\mathrm{Pt}$ and $\mathrm{Pd}$, and in less extent $\mathrm{Rh}$ and $\mathrm{Au}$ ), their limited availability, sensitivity to high temperatures, and poisoning by halogenated compounds, have long been motivating research for substitute catalysts. Metal oxides (mostly $\mathrm{Mn}, \mathrm{Co}$, $\mathrm{Cu}, \mathrm{Fe}$ and $\mathrm{Ni}$ ), which come in different forms, e.g., as single metal oxides, as mixed transition metal oxides or as a combination of noble and transition metal oxides, are a possible alternative to noble metals ${ }^{6}$. The use of bimetallic metal oxides, including $\mathrm{Cu}-\mathrm{Mn}, \mathrm{Cu}-\mathrm{Cr}, \mathrm{Mn}-\mathrm{Ni}, \mathrm{Ag}-\mathrm{Mn}, \mathrm{Ag}-\mathrm{Co}, \mathrm{Co}-\mathrm{Zn}$, etc. is also promising due to their enhanced activity, selectivity, thermal stability, and resistance to poisoning in comparison with the corresponding monometallic oxide systems. Some zeolites and mesoporous materials, such as MCM-41 (Mobil Composition of Matter No.41) and SBA-15 (Santa Barbara Amorophous -15) have also been investigated as catalysts used for carbon monoxide (CO) and VOC oxidation ${ }^{6}$. In general, metal oxides have quite high activity, especially at high temperatures, and they show greater resistance to poisoning in comparison to noble metal catalysts. However, they are less active than noble metals at low temperatures. Perovskite-type oxides, described by the general formula $\mathrm{ABO}_{3}$, like $\mathrm{LaCoO}_{3}, \mathrm{LaMnO}_{3}$ and $\mathrm{LaFeO}_{3}$, have attracted a lot of attention as potential catalysts for oxidation of carbon monoxide and various hydrocarbons ${ }^{10,11}$. It has been reported in litera- 
ture that their high catalytic activities are connected with the formation of positive holes and/or oxygen vacancies ${ }^{4}$.

Ceria, $\mathrm{CeO}_{2}$, owing to high mobility and oxygen storage capacity within the lattice, has been extensively investigated in different reaction systems, such as automotive exhaust purification (three-way catalysts, TWCs), low-temperature water-gas shift (WGS) reaction, low-temperature selective catalytic reduction of nitrogen monoxide (NO) with ammonia $\left(\mathrm{NH}_{3}\right)\left(\mathrm{NH}_{3}-\mathrm{SCR}\right), \mathrm{CO}$ oxidation, catalytic wet air oxidation (CWAO), catalytic wet peroxide oxidation (CWPO), oxygen sensors, oxygen permeation membrane systems, fuel cell processing, photocatalysis, as well as biotechnology and medicine $^{12-19}$. Tang et al. ${ }^{14}$ reported that the state of ceria in catalysts can be classified into three kinds according to their manner of use: i) as an active component or pure support to deposit active component(s), ii) as a bulk doping, and iii) as a surface loading component. Furthermore, its catalytic properties and morphology can be changed depending on the preparation method and preparation parameters. Different synthesis approaches have been reported in literature for the synthesis of ceria nanoparticles and films, including hydrolysis, precipitation, thermal deposition, flame synthesis, solgel, hydrothermal and solvothermal methods, etc. ${ }^{19}$ However, the hydrothermal method possesses numerous advantages, such as simplicity, affordability, and environmental benignity ${ }^{20}$.

The development of low-temperature catalysts with high selectivity and low preparation costs remains a challenging goal in the heterogeneous catalysis. In our previous investigation ${ }^{21}$ hydrothermal synthesis of $\mathrm{CeO}_{2}$ was optimized with respect to various process parameters in order to obtain a material with the greatest specific surface area. The optimization was done using Taguchi design. It was shown that the only significant factor for achieving high specific surface area is the hydrothermal synthesis temperature. In this paper, we report the properties of ceria obtained with optimized hydrothermal synthesis and its potential utilization as a catalyst for toluene oxidation.

\section{Experimental part}

\section{Chemicals}

$\mathrm{Ce}\left(\mathrm{SO}_{4}\right)_{2} \cdot 3 \mathrm{H}_{2} \mathrm{O}$ (Merck, Germany) and $\mathrm{NaOH}$ (Kemika, Croatia) were used for the ceria nanoparticles synthesis. Chemicals were of analytical grade and used without further purification.

All gases were of high purity $(99.9 \%)$ and supplied by UTP d.o.o (SOL Group). A mixture of tol- uene in nitrogen $\left(1 \mathrm{~g} \mathrm{~m}^{-3}\right)$ was used as the reactant, and synthetic air was used as the oxidant. All reactants and gases were used as received without further purification.

\section{Catalyst preparation}

Firstly, a $\mathrm{NaOH}$ solution with a concentration of $8 \mathrm{~mol} \mathrm{dm}^{-3}$ was prepared. An amount of 0.8 mmol of $\mathrm{Ce}\left(\mathrm{SO}_{4}\right)_{2} \cdot 3 \mathrm{H}_{2} \mathrm{O}$ was then dissolved in 56 $\mathrm{cm}^{3}$ of the $\mathrm{NaOH}$ solution, and placed in a $70-\mathrm{cm}^{3}$ Teflon-lined stainless-steel autoclave. The autoclave was tightly sealed and thermally treated at $120{ }^{\circ} \mathrm{C}$ for 16 hours in a temperature-controlled oven. After cooling, the product was centrifuged, and the precipitate was washed with demineralized water with the aid of sonification. The washing procedure was repeated three times, and the precipitate was then dried at $60{ }^{\circ} \mathrm{C}$ for $24 \mathrm{~h}$ in static air. It is important to emphasize that the synthesis was conducted using the plane hydrothermal process without additives that could contaminate ceria and reduce its catalytic activity.

\section{Catalyst characterization}

The crystal phase in the sample was identified by X-ray diffraction (XRD) analysis using Shimadzu XRD 6000 diffractometer with $\mathrm{CuK} \alpha$ radiation operated at $40 \mathrm{kV}$ and $30 \mathrm{~mA}$. Data were collected between 5 and $105^{\circ} 2 \theta$ in a step scan mode with steps of $0.02^{\circ} 2 \theta$ and counting time of $2 \mathrm{~s}$. In order to deconvolute individual contributions of crystallite size and lattice strain to diffraction peaks, broadening Williamson-Hall analysis ${ }^{22}$ was employed. According to Williamson and Hall, the crystallite size varies with $1 / \cos \theta$ and the strain is dependent on the $\tan \theta$ from the peak width. Therefore, the size and the strain contributions could be separated through the following equation:

$$
\beta_{h k l} \cos \theta=\frac{k \lambda}{D}+4 \varepsilon \sin \theta
$$

where $\beta_{\mathrm{hkl}}$ is the peak full width at half maximum corrected for instrumental broadening, $\theta$ is the Bragg angle, $\kappa$ is the shape factor (0.94 in case of spherical ceria particles), $\lambda$ is the $\mathrm{CuK} \alpha$ radiation wavelength, $D$ is the crystallite size, and $\varepsilon$ is the lattice strain.

The morphology of the prepared sample was investigated using transmission electron microscopy (TEM) device JEM-1400 Plus (JEOL) with accelerating voltage of $120 \mathrm{kV}$. Surface properties of the sample were determined based on the Brunauer-Emmet-Teller (BET) analysis using nitrogen $\left(\mathrm{N}_{2}\right)$ adsorption-desorption isotherms obtained on $\mathrm{Mi}$ cromeritics ASAP-2000 at $77 \mathrm{~K}$. The sample was previously degassed at $100{ }^{\circ} \mathrm{C}$ under a dynamic 
vacuum of $13 \mathrm{mPa}$ to remove any surface adsorbed residues. The surface area was calculated utilizing the desorption data. The UV-Vis spectrum of the prepared sample was obtained using diffuse reflectance spectroscopy (DRS) on Shimadzu UV$3101 \mathrm{PC}$ equipped with an integrating sphere. The spectrum was recorded at room temperature in the wavelength range of $200-800 \mathrm{~nm}$. Barium sulphate $\left(\mathrm{BaSO}_{4}\right)$ was used as a reference. The diffuse reflectance spectrum was transformed by performing a Kubelka-Munk transformation of the measured reflectance according to: $F(R)=(1-R)^{2} /(2 R)$, where $\mathrm{F}(\mathrm{R})$ is proportional to the extinction coefficient $(\alpha)$, and R is the reflectance of the "infinitely thick" layer of the solid ${ }^{23}$. The bandgap energy, $E_{g}$, was estimated by plotting modified Kubelka-Munk function, $(\mathrm{F}(\mathrm{R}) h v)^{\mathrm{n}}$, vs. photon energy $(h v)$, the socalled Tauc's plot, followed by extrapolation of the linear region of the Tauc's plot onto the energy axis. In the modified Kubelka-Munk function, $h$ is the Planck's constant $\left(4.13566733 \cdot 10^{-15} \mathrm{eV} \mathrm{s}\right)$, and $v$ is frequency, the quotient of light velocity $(c=$ $\left.299792458 \mathrm{~m} \mathrm{~s}^{-1}\right)$ and wavelength, $\left(\lambda / \mathrm{m}^{-1}\right)$. The exponent $n$ is associated with the electronic transition in the course of optical absorption process and is theoretically equal to $1 / 2$ and 2 for indirect and direct allowed transitions, respectively ${ }^{23}$.

\section{Catalytic activity tests}

The activity of the homemade catalyst was measured in an integral up-flow fixed bed reactor (I.D. $7 \mathrm{~mm}$ ) operating at atmospheric pressure. Toluene was chosen as a model VOC compound for catalytic oxidation. The catalyst $(0.05 \mathrm{~g})$ was placed in the reactor between two quartz wool plugs. The dead volumes on both ends of the catalyst bed were filled with inert metal inserts to minimize potential gas-phase reactions at higher reaction temperatures. The gas mixture consisted of toluene in nitrogen (1 $\mathrm{g} \mathrm{m}^{-3}$ of toluene in nitrogen, SOL Group, Italy) and air as the oxidant (UTP, Croatia). The reactor temperature was regulated by a thermo-controller (TC208 Series) connected to a thermocouple placed inside the reactor and the heaters around the reactor. The gas flow rates were regulated using mass flow controllers (Brooks).

Catalytic oxidation of toluene was carried out at isothermal conditions, constant inlet toluene concentration $\left(0.8 \mathrm{~g} \mathrm{~m}^{-3}\right)$, different total flow rates of the reaction mixture $\left(23-138 \mathrm{~mL} \mathrm{~min}^{-1}\right)$, and in the temperature range from 100 to $400{ }^{\circ} \mathrm{C}$. Space times were changed varying the total flow of the reaction mixture (toluene/nitrogen and air) over a constant amount of catalyst. The reactor effluent was analysed using an on-line gas chromatograph equipped with a flame ionization detector (FID) and a Carbowax $20 \mathrm{M}$ column $(250 / 177 \mathrm{~mm})$.
Since one of the most important properties of a catalyst is maintenance of its long-term activity, preliminary experiments were carried out to check catalyst stability. However, there was no significant change in catalyst activity, indicating a stable catalytic performance of $\mathrm{CeO}_{2}$ after long-term exposure to the reaction conditions.

\section{Results and discussion}

\section{Properties of the prepared catalyst}

Powder XRD patterns of the as-prepared sample and samples heated to $500{ }^{\circ} \mathrm{C}$ and $1000{ }^{\circ} \mathrm{C}$ are shown in Fig. 1. The sample was calcined at $500{ }^{\circ} \mathrm{C}$ for $2 \mathrm{~h}$ as thermal pre-treatment before catalytic activity measurements, while thermal treatment at $1000{ }^{\circ} \mathrm{C}$ for $4 \mathrm{~h}$ was done in order to provide a standard for instrumental XRD peak broadening. Patterns are indexed to ceria, $\mathrm{CeO}_{2}$ (ICDD PDF number 34-394). As may be observed, the diffraction peaks of the as-prepared sample (Fig. 1a) are notably broad, the broadness of the peaks of the sample heated to $500{ }^{\circ} \mathrm{C}$ (Fig. 1b) is reduced, while peaks of the sample heated to $1000{ }^{\circ} \mathrm{C}$ (Fig. 1c) are fully narrow. Generally, the broadness of the peaks is affected by crystallite size and lattice strain, both hav-

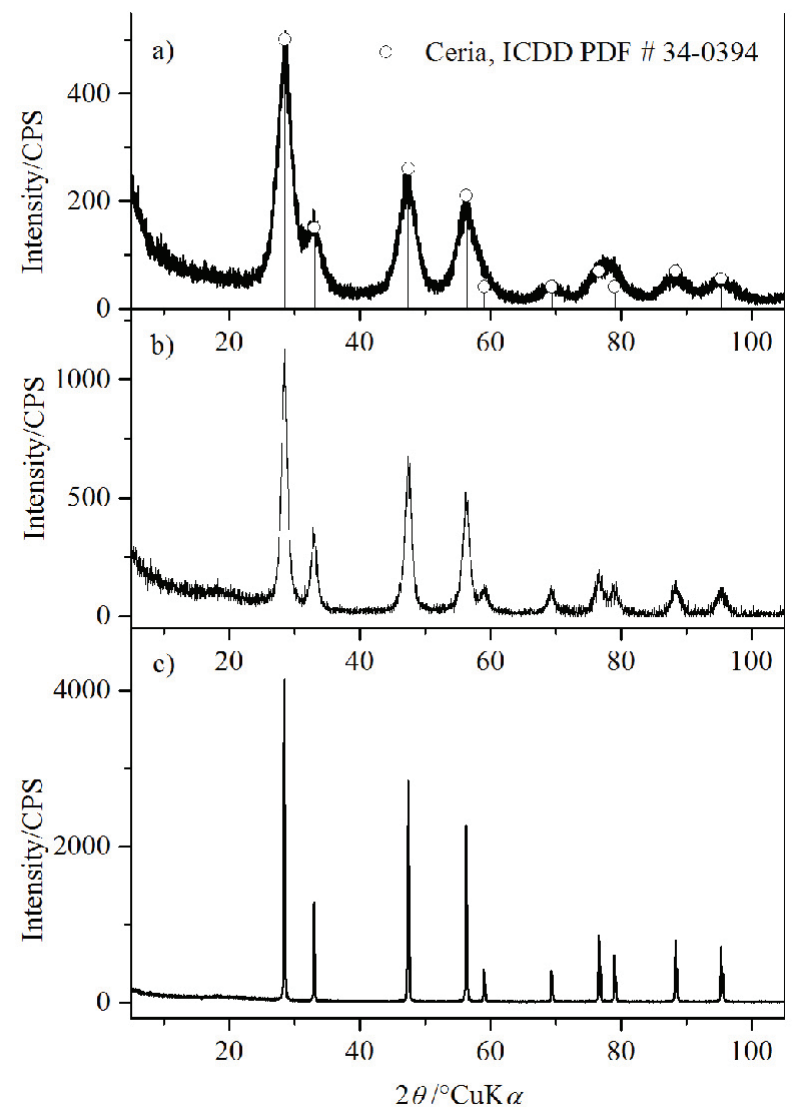

Fig. 1 - The diffraction pattern of a) as-prepared catalyst, b) catalyst heated to $500{ }^{\circ} \mathrm{C}, \mathrm{c}$ ) catalyst heated to $1000{ }^{\circ} \mathrm{C}$ 


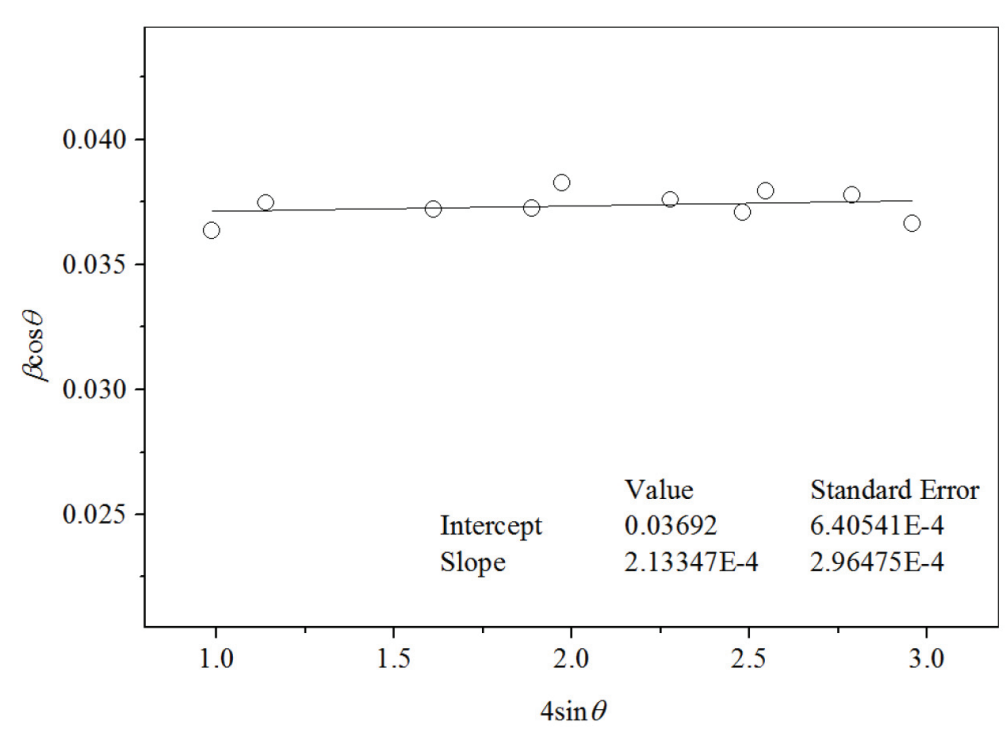

Fig. 2 - Williamson-Hall plot of the prepared catalyst

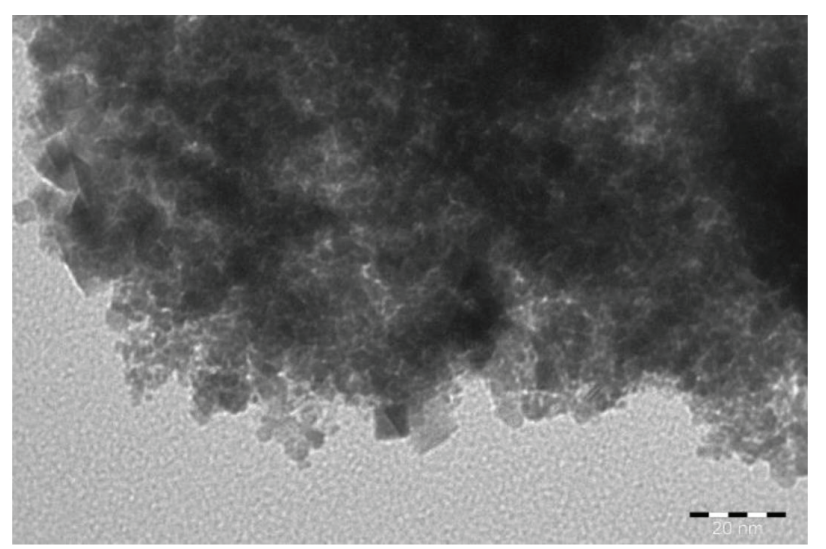

Fig. 3 - TEM micrograph of the prepared catalyst

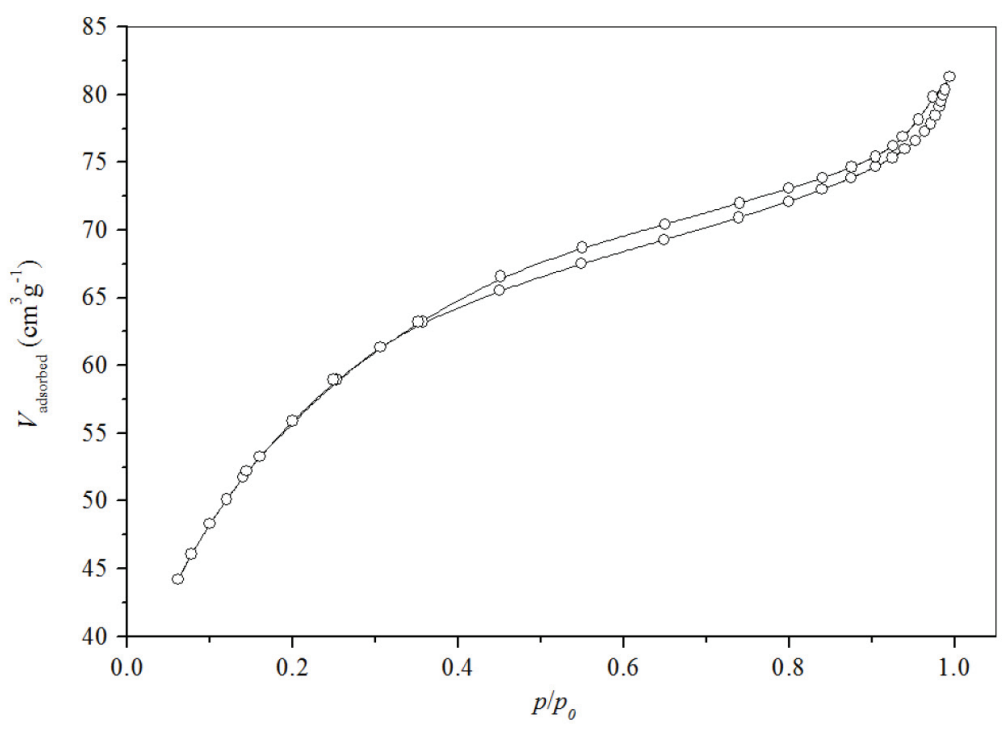

Fig. 4 - Nitrogen adsorption-desorption isotherms of the prepared catalyst

ing a profound influence on the properties of nanoparticles. Their contribution to the peak breadth could be separated through Williamson-Hall analy- sis. Therefore, peaks were deconvoluted and the obtained full width at half maxima and Bragg angles were used to construct Williamson-Hall plot.

The Williamson-Hall plot of the prepared catalyst is shown in Fig. 2. As may be observed, the broadening is dominated by crystallite size influence, while lattice strain contribution appears to be negligible. On the basis of Scherrer's formula, the average crystallite size was estimated to be $\sim 4 \mathrm{~nm}$. Beside morphology, crystallite and particle size are believed to play a key role in determination of ceria catalytic activity ${ }^{24}$. Thermal treatment to $500{ }^{\circ} \mathrm{C}$ yielded a considerable increase in crystallite size to $9 \mathrm{~nm}$ calculated through the Scherrer's formula. The crystallite size does not contribute to the broadness of the peaks of the sample heated to $1000{ }^{\circ} \mathrm{C}$, which is entirely a consequence of instrumental broadening.

The morphology of the prepared catalyst was characterized by TEM (Fig. 3). Heavily agglomerated nanometer-sized particles could be seen in the micrograph. Nanometer-sized particles could be observed at the edges of the agglomerate. However, based on the present micrograph, it was not possible to determine the average particle size or to compare it with the crystallite size calculated on the basis of XRD data.

The nitrogen adsorption-desorption isotherms of the prepared catalyst are given in Fig. 4. The isotherm could be classified as type $\mathrm{IV}^{25}$, although not typical, since it possess no final saturation plateau. The narrow hysteresis loop of isotherms presented in Fig. 4 could be classified as H3, often associated with particle aggregates ${ }^{25}$. The BET specific surface area of the prepared sample was calculated from the desorption isotherm, and yielded $201 \mathrm{~m}^{2} \mathrm{~g}^{-1}$, which is a quite satisfactory result.

Fig. 5 presents the UV-Vis reflectance spectrum of the prepared catalyst showing intense absorbance in the UV region and fair reflectance in the Vis region. Ceria is a direct semiconductor, and in order to obtain the value of the direct band gap, $(\mathrm{F}(\mathrm{R}) h v)^{2}$ was plotted as a function of photon energy, followed by extrapolation of the linear portion of the curve to abscissa (Inset in Fig. 5). The value of $3.19 \mathrm{eV}$ was obtained, which is precisely the value of the band gap of bulk ceria ${ }^{26}$. One would expect a considerable blue shift of the band gap due to the quantum confinement effect in small particles. However, Zhang et al. ${ }^{27}$ noted red-shift counteraction due to the dielectric confinement effect, yielding almost unchanged ceria nanocrystals band gap.

\section{Catalytic activity measurements}

In order to determine the catalytic oxidation properties of the prepared nanocrystalline ceria, cat- 


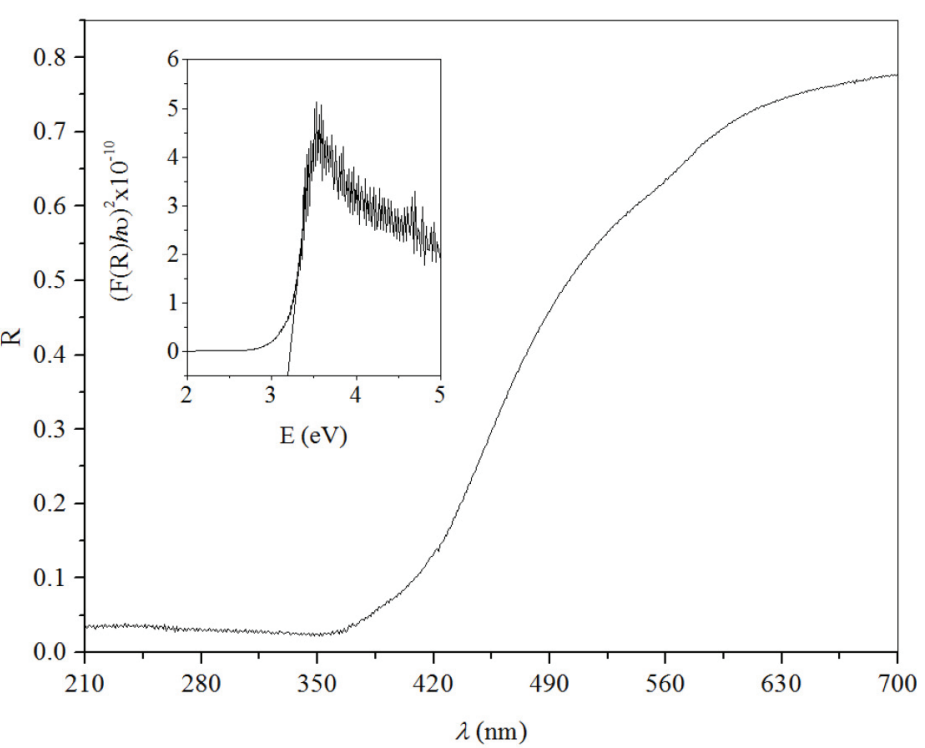

Fig. $5-U V-V i s$ diffuse reflectance spectrum of the prepared catalyst. Inset: Modified Kubelka-Munk function for the direct transition.

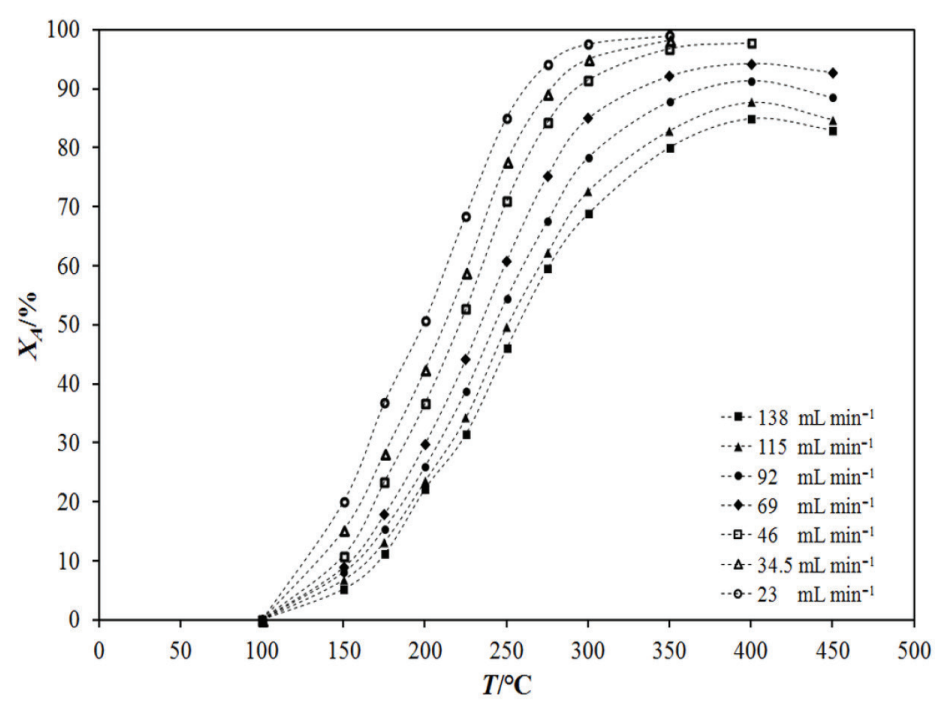

Fig. 6 - Influence of temperature and total flow rate of the reaction mixture on toluene conversion over $\mathrm{CeO}_{2}$

alytic oxidation of toluene was used as a model reaction. According to the literature, monocyclic aromatics, such as toluene, are generally oxidized around $200{ }^{\circ} \mathrm{C}$ over noble metals like platinum ${ }^{28}$. Ceria is a very active catalyst for toluene oxidation, since this reaction is essentially controlled by the presence of surface oxygen species, which facilitate the $\mathrm{C}-\mathrm{H}$ bond activation. To examine the possibility of thermal oxidation of toluene, blank tests at elevated temperatures without the catalyst were performed. It was found that there was no significant thermal degradation of toluene at temperatures lower than $300{ }^{\circ} \mathrm{C}$ at the total flow rates employed in this study. Catalytic activity results for toluene conversion over $\mathrm{CeO}_{2}$ obtained at different tempera- tures and total flow rates of the reaction mixture are presented in Fig. 6. As may be seen, $\mathrm{CeO}_{2}$ showed excellent catalytic performance giving $50 \%$ toluene conversion at a quite low temperature, e.g., at 200 ${ }^{\circ} \mathrm{C}$ to $250{ }^{\circ} \mathrm{C}$, depending on total flow rate of the reaction mixture.

It is evident that toluene conversion rapidly increases with the reaction temperature at all flow rates employed in this study. The increase in toluene conversion continued to a temperature of about $350{ }^{\circ} \mathrm{C}$, after which only a slight increase in conversion was noticed, but above $450{ }^{\circ} \mathrm{C}$ the conversion decreased. The explanation for the decrease in toluene conversion above $450{ }^{\circ} \mathrm{C}$ is probably related to the redox capability of cerium oxides $\left(\mathrm{Ce}^{4+} \rightleftarrows \mathrm{Ce}^{3+}\right)^{29}$. As known, with changes in the cerium oxidation state, $\mathrm{CeO}_{2}$ can participate in the formation of oxygen vacancies or defects in the crystal lattice due to the loss of oxygen or its electrons. The valence and defect structure of $\mathrm{CeO}_{2}$ is quite dynamic and may be changed in response to reaction conditions, especially at elevated temperatures and at low oxygen partial pressures ${ }^{14,19}$. Obviously, the redox properties of ceria and associated oxygen defects, such as oxygen vacancies, play significant roles in the reactivity of ceria for the catalytic oxidation of hydrocarbons. Operating at lower total flow rates leads to higher space times of the reaction mixture inside the reactor, and thus to higher toluene conversions, as is expected. It can also be seen that the space time of the reaction mixture in the reactor had no influence on the shape of the conversion-temperature curve itself.

\section{Mathematical model}

Although the gas-phase oxidation of toluene over different catalysts has been evaluated by many researchers, there are only a few papers in the literature related to the modelling of catalytic reactors used for this purpose. In this study, a simple one-dimensional (1D) pseudo-homogeneous model of the fixed bed tubular reactor was used to simulate the low-temperature toluene oxidation over $\mathrm{CeO}_{2}$, with special emphasis on the basic principles in the development of such a model.

\section{Assumptions and model equations}

As already mentioned previously, in this study catalytic oxidation of toluene was carried out using the powder form of $\mathrm{CeO}_{2}$ in the fixed bed reactor. Due to a small catalyst size (nanometer-sized particles) and a small catalyst mass used (only $0.05 \mathrm{~g}$ ), it follows that the catalytic layer was very thin. Under such working conditions (high flow velocity of the reaction mixture through the catalytic layer and small catalyst particle size), the following assump- 
tions were taken into account in the model development: the plug flow and steady-state conditions, as well as negligible resistance to the intraphase mass transfer. Due to the low concentration of toluene, and thus a small amount of heat generated by the reaction, the reaction was considered isothermal.

All these assumptions make it possible to use a simple one-dimensional pseudo-homogeneous model of the tubular reactor:

$$
-u \frac{\mathrm{d} c_{A}}{\mathrm{~d} z}=f\left(c_{A}\right)=r_{A}^{s} \rho_{b}
$$

where the rate of the reaction per unit mass of catalyst, $r_{A}^{s}$, and the reaction rate per unit volume of the reactor are associated with the bulk density of the catalyst, $\rho_{b}$, in order to ensure the consistency of the dimensions.

Catalytic oxidation of toluene was described with a simple first order kinetic model:

$$
r_{s} \rho_{b}=f\left(c_{A}^{s}\right)=k_{A} c_{A}^{s}
$$

\section{Solution method and model verification}

The numerical solution was based on the following procedure: the calculation began by converting the model equations (Eqs. 2 and 3) in the dimensionless form by introducing the following dimensionless variables:

$$
\begin{aligned}
& y_{A}=c_{A} / c_{A 0} \\
& \tau=\tau^{*} / \tau_{\max }^{*}
\end{aligned}
$$

After that, the model equation appeared in dimensionless form:

$$
-\frac{\mathrm{d} y_{A}}{\mathrm{~d} \tau}=\tau_{\max }^{*} \rho_{b} k_{A} y_{A}
$$

The corresponding kinetic model was given by Eq. 6 and the appropriate boundary conditions at the reactor inlet were given by Eq. 7:

$$
\begin{gathered}
r_{s} \rho_{b}=k_{A} y_{A}^{s} \\
\tau=0, \quad y_{A 0}=1, \quad y_{A}^{s}=1
\end{gathered}
$$

The only estimated parameter of the reactor model was the rate constant, $k_{A}$. Parameter estimation was carried out using a modified differential method and Nelder-Mead method of nonlinear optimization. Correlation criteria was the mean square root of differences between the experimentally measured concentrations of toluene and theoretical values provided by the model.

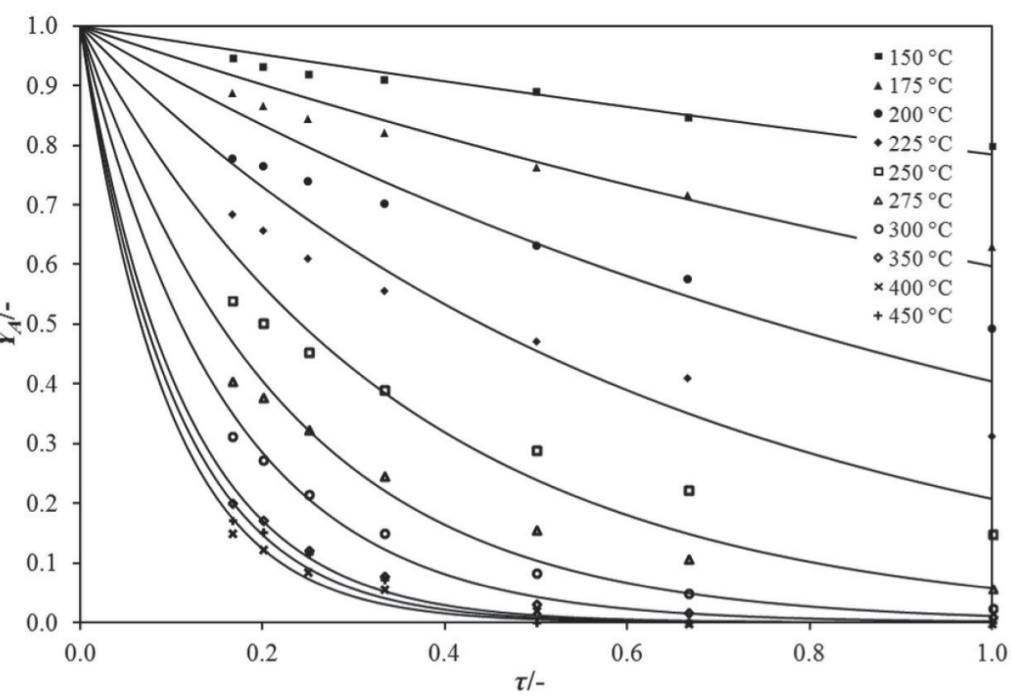

Fig. 7 - Comparison between experimental data (points) and the values predicted by the proposed model (lines) over $\mathrm{CeO}_{2}$ at different temperatures

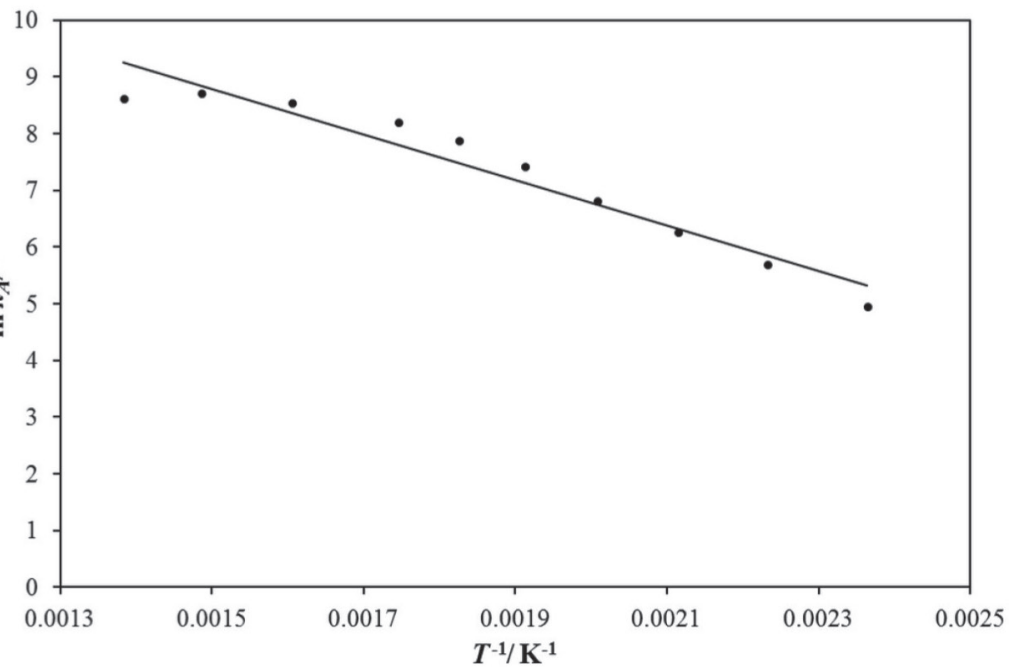

Fig. 8-Activation energy, $E_{a}$ and the frequency factor, $A_{r}$ determination

The proposed model was verified by comparing the experimental data (points) with theoretical predictions obtained using the proposed model (lines), illustrated in Fig. 7. Estimated kinetic parameters of the reactor model and the mean square root deviations, $\mathrm{SD}$, are listed in Table 1.

Generally, good agreement between the experimental data and theoretical predictions was achieved. As expected, the rate constants, $k_{A}$, increased with the increase in reaction temperature. The apparent activation energy for toluene oxidation over the $\mathrm{CeO}_{2}$ catalyst was calculated based on the Arrhenius equation (Fig. 8). The calculated activation energy, $E_{a}$, was $33.24 \mathrm{~kJ} \mathrm{~mol}^{-1}$, while the frequency factor, $A_{r}$ was $2.61 \cdot 10^{6} \mathrm{~min}^{-1}$. The obtained value of the activation energy is comparable to the 
Table 1 -Estimated values of the rate constants, $k_{4}$ and the mean square deviations, $S D$, between the experimentally obtained and theoretically predicted values

\begin{tabular}{c|c|c}
\hline$T,{ }^{\circ} \mathrm{C}$ & $k_{A}, \mathrm{~min}^{-1}$ & $\mathrm{SD} \cdot 10^{3}$ \\
\hline 150 & 141.28 & 4.81 \\
175 & 298.48 & 8.23 \\
200 & 525.74 & 0.20 \\
225 & 910.92 & 0.22 \\
250 & 1661.18 & 0.21 \\
275 & 2625.27 & 0.15 \\
300 & 3648.45 & 8.83 \\
350 & 5132.68 & 5.59 \\
400 & 6071.79 & 5.11 \\
450 & 5567.69 & 5.42 \\
$A_{r}=2.61 \cdot 10^{6} \mathrm{~min}^{-1} ; E_{a}=33.24 \mathrm{~kJ} \mathrm{~mol}^{-1}$ \\
\hline
\end{tabular}

value $\left(37-43 \mathrm{~kJ} \mathrm{~mol}^{-1}\right)$ reported by Tan et al. ${ }^{30}$ for toluene oxidation on cerium-supported gold and palladium alloy $\left(0.90-0.93 \mathrm{Au}_{\mathrm{x}} \mathrm{Pd} / \mathrm{CZY}\right)$ nanoparticles, and much lower than the apparent $E_{a}$ value (88 $\mathrm{kJ} \mathrm{mol}^{-1}$ ) obtained over the unsupported ceria-zirconia-yttria solid solution, CZY (without supported noble metals) and other catalysts ${ }^{31,32}$.

\section{Conclusions}

Ceria catalyst was prepared, and its structure, morphology, texture, band gap and catalytic performance were evaluated.

Pure ceria with a crystallite size of $4 \mathrm{~nm}$ was obtained. Particles are heavily agglomerated with sizes roughly consistent with the calculated crystallite size. Specific surface area of the prepared catalyst yielded $201 \mathrm{~m}^{2} \mathrm{~g}^{-1}$, while the band gap of 3.2 $\mathrm{eV}$ was calculated.

To evaluate the catalytic performances of the prepared ceria, the catalytic oxidation of toluene, chosen as a VOC model component, was investigated at different reaction conditions. The prepared catalyst was highly active in toluene oxidation, even at quite low reaction temperatures. The results presented in this study demonstrate that the hydrothermally prepared ceria is a good candidate for the VOC's abatement at low temperatures. However, additional investigations should be performed on ceria-based mixed oxides and related materials for their enhanced performance in catalytic oxidation at elevated temperatures.

A simple and practical 1D pseudo-homogeneous reactor model was applied to describe the ex- perimental system within the reaction conditions range. A satisfactory degree of correlation between the experimental data and theoretical predictions was obtained, indicating that this model can be used to analyse the influence of different operating parameters on the catalytic performance.

\section{ACKNOWLEDGEMENTS}

The authors acknowledge the financial support of the University of Zagreb. Special thanks go to Karolina Maduna for performing TEM analysis at Abo Akademi in Finland.

\section{Symbols}

$A_{r} \quad-$ frequency factor, $\min ^{-1}$

c - speed of light in the vacuum, $c=299792458$ $\mathrm{m} \mathrm{s}^{-1}$

$c_{A}-$ concentration in the fluid phase, $\mathrm{mol} \mathrm{cm}^{-3}$

$c_{A}^{s} \quad-$ concentration on the catalyst surface, $\mathrm{mol} \mathrm{cm}{ }^{-3}$

$c_{A 0}-$ initial concentration in the fluid phase, $\mathrm{mol} \mathrm{cm}{ }^{-3}$

D $\quad$ - crystallite size, $\mathrm{nm}$

$d_{\text {pore }} \quad$ - average pore diameter, $\mathrm{nm}$

$E_{a} \quad$ - activation energy, $\mathrm{kJ} \mathrm{mol}^{-1}$

$E_{g} \quad$ - band gap energy, eV

$\mathrm{F}(\mathrm{R}) \quad$ - Kubelka-Munk function

$h \quad$ - Planck's constant, $4.13566733 \mathrm{eV} \mathrm{s}$

$k_{A} \quad-$ rate constant, $\min ^{-1}$

$\kappa \quad-$ Scherrer's equation shape factor (for the case of spherical particles with cubic symmetry 0.94)

$n$ - exponent associated with electronic transition in the course of optical absorption process $(1 / 2$ and 2 for indirect and direct allowed transitions, respectively)

$p / p_{0} \quad-$ relative pressure, -

$r_{s} \quad-$ surface reaction rate, $\mathrm{mol} \mathrm{g}_{\mathrm{cat}}{ }^{-1} \mathrm{~min}^{-1}$

$\mathrm{R}-$ reflectance of the "infinitely thick" layer of the solid

SD - root mean square deviation, -

T $\quad$ - temperature, ${ }^{\circ} \mathrm{C}$

u $\quad$ - linear velocity, $\mathrm{cm} \mathrm{min}^{-1}$

$V_{\text {adsorbed }}$ - volume of adsorbed $\mathrm{N}_{2}, \mathrm{~cm}^{3} \mathrm{~g}^{-1}$

$X_{A} \quad-$ conversion, $\%$

$y_{A} \quad-$ molar fraction of compound, -

$y_{\mathrm{A}}^{s}-$ molar fraction of compound on the catalyst surface, -

$y_{\mathrm{A} 0}-$ initial molar fraction of compound in the fluid phase, -

$z \quad-$ reactor axial coordinate, $\mathrm{cm}$ 


\section{Greek letters}

$\rho_{b} \quad-$ bulk density of catalyst, $\mathrm{g}_{\text {cat }} \mathrm{cm}^{-3}$

$\tau^{*} \quad-$ space time, $\min$

$\tau_{\max }^{*}-$ maximum space time, min

$\tau \quad-$ dimensionless space time, -

$\beta_{\mathrm{hkl}}-$ diffraction peak full width at half maximum corrected for instrumental broadening, rad

$\varepsilon \quad-$ lattice strain, -

$\theta \quad-$ Bragg angle, rad

$\lambda-\mathrm{CuK} \alpha$ radiation wavelength, $\mathrm{nm}$

$v \quad-$ frequency, $\mathrm{s}^{-1}$

\section{References}

1. Miran, H. A., Altarawneh, M., Jiang, Z.-T., Oskierski, H., Almatarneh, M., Dlugogorski, B. Z., Decomposition of selected chlorinated volatile organic compounds by ceria $\left(\mathrm{CeO}_{2}\right)$, Catal. Sci. Technol. 7 (2017) 3902. doi: https://doi.org/10.1039/C7CY01096F

2. Wang, H., Yang, W., Tian, P., Zhou, J., Tang, R., Wu, S., A highly active and anti-coking $\mathrm{Pd}-\mathrm{Pt} / \mathrm{SiO}_{2}$ catalyst for catalytic combustion of toluene at low temperature, Appl. Catal. A Gen. 529 (2017) 60. doi: https://doi.org/10.1016/j.apcata.2016.10.016

3. Torrente-Murciano, L., Solsona, B., Agouram, S., Sanchis, R., López, J. M., Garcia, T., Zanella, R., Low temperature total oxidation of toluene by bimetallic Au-Ir catalysts, Catal. Sci. Technol. 7(13) (2017) 2886. doi: https://doi.org/10.1039/C7CY00635G

4. Hanegan, C. S., Hutchings, G. J., Taylor, S. H., The Destruction of Volatile Organic Compounds by Heterogeneous Catalytic Oxidation, in Spivey, J. J., Roberts, G. W. (Eds.), Catalysis, Vol. 17, The Royal Society of Chemistry, Cambridge, 2004, pp 105-151. doi: https://doi.org/10.1039/9781847553294-00105

5. Barbero, B. P., Costa-Almeida, L., Sanz, O., Morales, M. R., Cadus, L. E., Montes, M., Washcoating of metallic monoliths with a $\mathrm{MnCu}$ catalyst for catalytic combustion of volatile organic compounds, Chem. Eng. J. 139(2) (2008) 430 .

doi: https://doi.org/10.1016/j.cej.2007.12.033

6. Szegedi, A., Popova, M., Minchev, C., Catalytic activity of $\mathrm{Co} / \mathrm{MCM}-41$ and $\mathrm{Co} / \mathrm{SBA}-15$ materials in toluene oxidation, J. Mater. Sci. 44 (2009) 6710. doi: https://doi.org/10.1007/s10853-009-3600-y

7. da Silva, A. G. M., Fajardo, H. V., Balzer, R., Probst, L. F. D., Prado, N. T., Camargo, P. H. C., Robles-Dutenhefner, P. A., Efficient ceria-silica catalysts for BTX oxidation: Probing the catalytic performance and oxygen storage, Chem. Eng. J. 286 (2016) 369.

doi: https://doi.org/10.1016/j.cej.2015.10.097

8. de Nevers, N., Air Pollution Control Engineering, McGraw Hill, Inc., New York, 1995, pp. 275-327.

9. Cooper, C. D., Alley, F. C., Air Pollution Control: A design Approach, Waveland Press, Inc., Long Grove, 2002, pp. 321-359.

10. Liang, J. J, Chen, C.-H., Catalytic oxidation of toluene and methyl ethyl ketone over $\mathrm{La}-\mathrm{Sr}-\mathrm{Mn}$ perovskite catalysts, J. of the Chinese Institute of Environmental Engineering 15(2) (2005) 111
11. Wachs, I. E., Routray, K., Catalysis science of bulk mixed oxides, ACS Catal. 2(6) (2012) 1235. doi: https://doi.org/10.1021/cs2005482

12. Kaspar, J., Fornasiero, P., Graziani, M., Use of $\mathrm{CeO}_{2}$-based oxides in the three-way catalysis, Catal. Today $\mathbf{5 0}^{2}(1999)$ 285.

doi: https://doi.org/10.1016/S0920-5861(98)00510-0

13. Fu, Q., Saltsburg, H., Flytzani-Stephanopoulo, M., Active nonmetallic $\mathrm{Au}$ and $\mathrm{Pt}$ species on ceria-based water-gas shift catalysts, Science 301 (2003) 935. doi: https://doi.org/10.1126/science.1085721

14. Tang, C., Zhang, H., Dong, L., Ceria-based catalysts for low-temperature selective catalytic reduction of NO with $\mathrm{NH}_{3}$, Catal. Sci. Technol. 6 (2016) 1248. doi: https://doi.org/10.1039/C5CY01487E

15. Jasinski, P., Suzuki, T., Anderson, H. U., Nanocrystalline undoped ceria oxygen sensor, Sens. Actuators B Chem. 95(1-3) (2003) 73. doi: https://doi.org/10.1016/S0925-4005(03)00407-6

16. Yin, X., Hong, L., Liu, Z. L., Oxygen permeation through the $\mathrm{LSCO}-80 / \mathrm{CeO} 2$ asymmetric tubular membrane reactor, J. Membr. Sci. 268 (2006) 2. doi: https://doi.org/10.1016/j.memsci.2005.06.005

17. Sun, C. W., Stimming, U., Recent anode advances in solid oxide fuel cells, J. Power Sources 171(2) (2007) 247. doi: https://doi.org/10.1016/j.jpowsour.2007.06.086

18. Asati, A., Santra, S., Kaittanis, C., Nath, S., Perez, J. M., Oxidase-like activity of polymercoated cerium oxide nanoparticles, Angew. Chem. Int. Ed. 48 (2009) 2308. doi: https://doi.org/10.1002/anie.200805279

19. Sun, C., Li, H., Chen, L., Nanostructured ceria-based materials: synthesis, properties and applications, Energy Environ. Sci. 5 (2012) 8475. doi: https://doi.org/10.1039/c2ee22310d

20. Deng, J., Chang, L., Wang, P., Zhang, E., Ma, J., Wang, T., Preparation and magnetic properties of $\mathrm{CoWO}_{4}$ nanocrystals, Cryst. Res. Technol. 47(9) (2012) 1004. doi: https://doi.org/10.1002/crat.201200130

21. Kurajica, S., Minga, I., Guliš, M., Mandić, V., Simčić, I., High surface area ceria nanoparticles via hydrothermal synthesis experimental design, J. Nanomater. 2016 (2016) 1. doi: https://doi.org/10.1155/2016/7274949

22. Suranarayana, C., Norton, M. G., X-Ray Diffraction: A Practical Approach. Springer, New York, 1998, pp. 207221. doi: https://doi.org/10.1007/978-1-4899-0148-4_9

23. Minga, I., Kurajica, S., Mandić, V., Thermal evolution process, properties and photocatalytic activity of sol-gel derived nanocrystalline anatase in dye degradation process, Acta Graphica 236 (2015) 11.

24. López, J. M., Gilbank, A. L., García, T., Solsona, B., Agouram, S., Torrente-Murciano, $L$., The prevalence of surface oxygen vacancies over the mobility of bulk oxygen in nanostructured ceria for the total toluene oxidation, Appl. Catal. B 174-175 (2015) 403. doi: https://doi.org/10.1016/j.apcatb.2015.03.017

25. Thommes, M., Kaneko, K., Neimark, A. V., Olivier, J. P., Rodriguez-Reinoso, F., Rouquerol, J., Sing, K. S. W., Physisorption of gases, with special reference to the evaluation of surface area and pore size distribution (IUPAC Technical Report), Pure Appl. Chem. 9-10 (2015) 1051. doi: https://doi.org/10.1515/pac-2014-1117

26. Kumar, E., Selvarajan, P., Muthuraj, D., Synthesis and characterization of $\mathrm{CeO}_{2}$ nanocrystals by solvothermal route, Mat. Res. 16 (2013) 269. doi: https://doi.org/10.1590/S1516-14392013005000021 
27. Zhang, Y.-W., Si, R., Lao, C-S., Kou, Y., Facile alcoholothermal synthesis, size dependent ultraviolet absorption, and enhanced $\mathrm{CO}$ conversion activity of ceria nanocrystals, Journal of Physical Chemistry B 107 (2003) 10159 doi: https://doi.org/10.1021/jp034981o

28. Barbier Jr, J., Duprez, D., Oxidation of CO and Hydrocarbons in Exhaust Gas Treatments, in: Duprez, D., Cavalli, F. (Eds.), Handbook of Advanced Methods and Processes in Oxidation Catalysis-From Laboratory to Industry, Imperial College Press, London, 2014, pp. 1-24. doi: https://doi.org/10.1142/9781848167513_0001

29. Zhang, D., Du, X., Shi, L., Gao, R., Shape-controlled synthesis and catalytic application of ceria nanomaterials, Dalton Trans. 41 (2012) 14455.

doi: https://doi.org/10.1039/c2dt31759a
30. Tan, W., Deng, J., Xie, S., Yung, H., Jiang, Y., Guo, G., Dai, $H$., $\mathrm{Ce}_{0.6} \mathrm{Zr}_{0.3} \mathrm{Y}_{0.1} \mathrm{O}_{2}$ nanorod supported gold and palladium alloy nanoparticles: high performance catalysts for toluene oxidation, Nanoscale 7 (2015) 8510. doi: https://doi.org/10.1039/C5NR00614G

31. Rioseco, F., Radovic, L., García, X., Gordon, A., Pechhi, $G$., Effect of $\mathrm{Ag}$ addition on the thermal stability and catalytic properties of $\mathrm{LaFeO}_{3}$ perovskite, J. Chil. Chem. Soc. 55(1) (2010) 44

doi: https://doi.org/10.4067/S0717-97072010000100011

32. Deng, Y.-F., Ren, T.-Z., Yuang, Z.-Y., Mesoporous manganese oxide nanoparticles for the catalytic total oxidation of toluene, Reac. Kinet. Mech. Cat. 108 (2013) 507. doi: https://doi.org/10.1007/s11144-012-0528-Z 